\title{
Eosinophilic Gastrointestinal Disorders: an Experience in a tertiary Care Rural Hospital
}

\author{
Wasim.M. Khatib ${ }^{1}$, Sunil.V. Jagtap ${ }^{2}$, Dhirajkumar.B. Shukla ${ }^{1}$, \\ Chetan Khurana ${ }^{3}$ \\ ${ }^{1}$ Assistant Professor, Department of Pathology, KIMS, Karad \\ ${ }^{2}$ Professor, Department of Pathology, KIMS, Karad \\ ${ }^{3}$ Assistant Lecturer, Department of Pathology, KIMS, Karad
}

\begin{abstract}
Background:- Primary Eosinophilic Gastrointestinal Disorders are a rare entity with an obscure etiology. As simple as they sound, however, they require high degree of clinical suspicion as they can mimic various disorders of gastrointestinal tract. Here in we present our experience in a rural tertiary care hospital.
\end{abstract}

Materials and Method:-All diagnosed cases of Eosinophilic gastrointestinal disorders from June 2009 to May 2014 were included in the study. The cases were studied according to the criteria led down by Talley et. al.

Klein's classification was used to segregate and study the cases.

Result:- We received four endoscopic biopsies; one from stomach and jejunum each; and two from ileum. Eleven appendicectomy and two hemicolectomy specimens respectively were also received by the Department of Pathology of our hospital. Majority of the cases showed mucosal involvement. Appendix was the most commonly affected organ. The overall response to treatment was better with a few exceptions.

Conclusion:- Primary Eosinophilic Gastrointestinal Disorders is a diagnosis of exclusion. Proper diagnostic modalities and high degree of suspicion is needed for precise diagnosis. Treatment modalities have bettered over the years with better patient response.

Keywords:-Eosinophilic gastrointestinal disorders, Appendix, Stomach, Eosinophilia.

\section{Introduction}

Eosinophilic gastroenteritis by a few workers is used synonymously for Eosinophilic gastrointestinal disorders which encompass Eosinophilic esophagitis, Eosinophilic gastritis, Eosinophilic enteritis and Eosinophilic colitis ${ }^{1}$. It is a rare inflammatory disease of obscure etiology, the pathogenesis of which is yet to be completely understood. Although the name suggests Gastroenteritis, virtually any part of gastrointestinal tract can be affected. The prevalence of this entity is sporadic, however, familial occurrence has also been noted with a male preponderance and most common age of presentation in third decade ${ }^{2,3,4}$. Food allergies, infestations, drug intake, malignancies play significant role in eosinophilia. Hence, high degree of suspicion is required for proper diagnosis and treatment.

\section{Materials and Method}

All diagnosed cases of Eosinophilic gastrointestinal disorders from June 2009 to May 2014 were included in the study.

Exclusion Criteria:- All cases having secondary causes of eosinophilia namely: Parasitic infections, History of drug intake, Inflammatory Bowel Diseases, Malignancies etc.

The cases were studied according to the criteria led down by Talley et al.

The clinical details including demographic details, dietary habits, presenting symptoms were all studied. Peripheral Eosinophilia,if present, was noted. Known cases of allergy, History of drug intake and stool samples were noted to ascertain primary eosinophilic gastrointestinal disorders. 
We received endoscopic biopsies, specimen from various sites and these were studied. After clinical, hematological and radiological investigations, the final diagnosis was given only after histopathological examination.

Klein's classification was used to segregate and study the cases.

Observations and Result:- We received four endoscopic biopsies; one from stomach and jejunum each; and two from ileum. Eleven appendicectomy and two hemicolectomy specimens respectively were also received by the Department of Pathology of our hospital. (Table no. 1).

Table No.1 Distribution of sites affected

\begin{tabular}{|l|l|}
\hline \multicolumn{1}{|c|}{ SITE } & \multicolumn{1}{c|}{ No. of Cases } \\
\hline Stomach & 01 \\
\hline Jejunum & 01 \\
\hline Ileum & 02 \\
\hline Appendix & 11 \\
\hline Colon & 02 \\
\hline
\end{tabular}

A total of 17 cases were diagnosed with eosinphilic gastrointestinal disorders. Male preponderance was noted with 10 cases, whereas 7 cases were noted in females. Mean age of presentation was noted in third decade.

Hematological examination revealed peripheral eosinophilia in 15 cases. Abdominal pain was the most common presenting symptom followed by diarrhea, nausea and vomiting(Table no.2). Majority of the males presented with abdominal pain, whereas females presented with diarrhea, abdominal distension, nausea and vomiting. There was a single case of an 88 years old male who presented with intestinal obstruction along with pain in abdomen. On investigation of this case, the computed tomography scans showed thickening of the wall of sigmoid colon with ascites.

Table No.2 Details of cases of Eosinophilic Gastrointestinal Disorders

\begin{tabular}{|c|c|c|c|c|c|}
\hline $\begin{array}{c}\text { Number of } \\
\text { cases }\{\mathrm{n}=17\}\end{array}$ & $\begin{array}{c}\text { Abdominal } \\
\text { pain }\end{array}$ & Diarrhea & $\begin{array}{c}\text { Bloating / } \\
\text { Fullness }\end{array}$ & Nausea/ vomiting & PR Bleeding \\
\hline Male $(10)$ & 07 & 00 & 00 & 01 & 01 \\
\hline Female $(07)$ & 02 & 02 & 01 & 02 & 00 \\
\hline Total & 09 & 02 & 01 & 03 & 01 \\
\hline
\end{tabular}

Klein's classification was used to segregate the cases according to infiltration of the bowel wall by eosinophils as (i) Mucosal (ii) Muscular (iii) Subserosal.(Table No. 3). According to this criteria,most common presentation was mucosal followed by serosal type.

Table No.3 Case Characterstics at various sites

\begin{tabular}{|l|l|l|l|l|l|l|}
\hline $\begin{array}{l}\text { Site/ Klein's } \\
\text { Classification }\end{array}$ & Stomach & Jejunum & Ileum & Appendix & Colon & Total \\
\hline Mucosal & 00 & 00 & 02 & 06 & 00 & 08 \\
\hline Muscular & 00 & 01 & 00 & 02 & 02 & 05 \\
\hline Subserosal & 01 & 00 & 00 & 03 & 00 & 04 \\
\hline
\end{tabular}

We received a gastric biopsy of a 30 years old female who presented with nausea and vomiting which was at times bilious in nature. Upper gastrointestinal scopy could not reveal any focal lesion throughout the upper gastrointestinal tract. However biopsies were taken from suspected areas in the stomach which were sent for histopathological examination. Ultrasonography was the most commonly employed radiological investigation in all these cases. Similar endoscopic biopsies were taken from the jejunum and ileum; and were sent for histopathological examination. 
There were 11 appendicectomy specimens received in our department of which 6 showed mucosal, 3 showed serosal whereas 2 revealed muscular infiltration by eosinophils respectively.

Average number of eosinophils noted were more than or equal to $25 / \mathrm{hpf}$.

We received 2 hemicolectomy specimens one of which has been described whereas the other was of a 50 years old female who presented with diarrhea and bleeding per rectum. Radiological investigations revealed mild to moderate thickening of bowel wall. Of the 17 patients, follow up of 12 patients was possible. Follow up was done for $>1$ year(12-18 months). All the patients had been initiated with steroid therapy. At the time of last follow up, 8 patients underwent resolution. However, they were still maintained on low dose steroids. Three patients underwent multiple episodes of relapse, whereas, one patient died within six months of therapy.

Discussion:-Primary Eosinophilic Gastrointestinal Disorders are defined as disorders that selectively effect the gastrointestinal tract with eosinophil rich inflammation in the absence of known causes of eosinophilia (drug intake, parasitic infections ,malignancies etc. ${ }^{2}$. Family of Eosinophilic Gastrointestinal Disorders comprises of Eosinophilic esophagitis, Eosinophilic Gastritis, Eosinophilic Gastroenteritis, Eosinophilic enteritis and Eosinophilic Colitis ${ }^{2}$. In 1937, Kaijser described Eosinophilic Gastroenteritis for the first time ${ }^{1,4,5}$. In 1970, Klein et al. defined the three patterns of disease manifestations in Eosinophilic gastrointestinal disorders ${ }^{2,5}$. Mucosal form is the most common form of Eosinophilic Gastrointestinal disorders characterized by vomiting, abdominal pain and diarrhea predominantly.

(i) Muscular form characterized by infiltration of eosinophils in muscular layer leading to obstructive symptoms.

(ii) Serosal form which is the least common and characterized by exudative ascites.

A standard diagnostic criteria or International diagnostic guidelines donot exist for Eosinophilic Gastroenteritis or Eosinophilic Colitis. However, Guidelines for Eosinophilic esophagitis do exist.

\section{Diagnosis of Eosinophilic esophagitis requires:}

(i) Esophageal dysfunction.

(ii) Dense Eosinophilic infiltrate (> 15 eosinophils / hpf) that persists at least after 8 weeks of proton pump inhibitors treatment.

(iii) Exclusion of differential diagnosis.

\section{The diagnostic criteria employed for Eosinophilic Gastrointestinal Disorders are predominantly} based on the criteria formulated by Talley et al. ${ }^{5,6}$

(i) The presence of gastrointestinal symptoms.

(ii) Biopsies demonstrating eosinophilic infiltration of one or more areas of gastrointestinal tract.

(iii) No evidence of parasitic or extra-intestinal disease.

The diagnosis of Eosinophilic gastrointestinal disorders is more so; a diagnosis of exclusion with a variety of lesions which can mimic the same ${ }^{8}$.( Table no. 4) The pathogenesis of Eosinophilic gastrointestinal disorders is still not well understood. However, role of eosinophilic major proteins cannot be over ruled.

Allergies, Atopy, Asthma and elevated serum IgE levels play a role in hypersensitivity reactions of Eosinophilic gastrointestinal disorders9. 
Table no. 4 Other diseases that should be differentiated from Eosinophilic Gastroenteritis

\begin{tabular}{|c|l|}
\hline 1 & $\begin{array}{l}\text { Intestinal parasites: Infection with Ancylostoma, Anisakis, Ascaris, Strongyloides, } \\
\text { Toxocara,Trichiura,Capillaria,Basidiobolomycosis,and Trichinella can cause } \\
\text { gastrointestinal symptoms and peripheral eosinophilia; infection with the dog hookworm, } \\
\text { Ancylostoma caninum can mimic Eosinophilic Gastroenteritis clinically and pathologically } \\
\text { with eosinophilic infiltration of the gut wall and ascites }\end{array}$ \\
\hline 2 & Malignancy:lymphoma, gastric cancer, and colon cancer \\
\hline 3 & $\begin{array}{l}\text { Inflammatory bowel disease: Crohn disease associated with peripheral eosinophilia and/or } \\
\text { an eosinophil-rich tissue infiltrate(rare) }\end{array}$ \\
\hline 4 & Hypereosinophilic syndrome \\
\hline 5 & Polyarteritis nodosa \\
\hline 6 & Eosinophilic granulomatosis with polyangitis \\
\hline 7 & Eosinophilic granuloma (Langerhans cell histiocytosis) \\
\hline
\end{tabular}

Role of various cytokines such as IL-3, IL-4, GM-CSF and eotoxin has also been suggested in few studies. ${ }^{10,11}$

The laboratory investigations range from peripheral blood eosinophilia, IgE estimation, stool studies for parasites, LFT ,RFT, pulmonary function and ascitic fluid analysis.

Peripheral Eosinophilia may or maynot be associated with Eosinophilic gastrointestinal disorders. However definitive diagnosis of Eosinophilic gastrointestinal disorders requires histological evidence of infiltration. As confirmed by biopsies with the cut off value being arbitrarily set at more than or equal to $20 / \mathrm{hpf}^{4,5,7}$

Systemic and topical corticosteroids, leukotriene receptor antagonists, allergy elimination and diet therapy are the treatment modalities employed.

Newer treatment modalities such as Anti IL-5 therapy, Anti- TNF therapy have been approved recently and are showing positive outcomes ${ }^{2}$.

\section{Conclusion}

A diagnosis of exclusion, the domain of Eosinophilic Gastrointestinal disorders need to be explored further. Extensive clinical history, proper radiological and hematological investigations are a must. The gold standard of diagnosis rests with histopathological examination. Exact diagnosis in chronic and relapsing gastro-intestinal symptoms is imperative as treatment modalities are different for individual conditions and for Eosinophilic gastrointestinal disorders.

NOTE :- one (1) Male presented with obstruction and abdominal pain.

\section{References}

[1]. RajkumarBharaniK ,Anbarasu S, Essaki M, Padmavathy A. Eosinophilic gastroenteritis presenting as acute small intestinal obstruction: A case report Int. J. Med Sci. Public Health 2014;3(9).

[2]. Jawairia M, Shahzad G, Mustacchia P. Eosinophilic gastrointestinal disease , Review and update. ISRN Gastroenterol 2012;2012:463689.

[3]. Ingle SB, Hinge Ingle CR. Eosinophilic gastroenteritis: An unusual type of gastroenteritis. World J. GastroEnerol 2013;19:5061-6.

[4]. Chen MJ, Chu CH, Lin SC, Shih SC, Wang TE. EosinophilicGastroenteritis : Clinical experience with 15 patients. World J. Gastroenterol 2003;9:2813-6.

[5]. Baig MA, Qadir A, Rasheed J. A review of esinophilic gastroenteritis. Journal of Natl. Med. Assoc. 2006;98:1616-9.

[6]. Talley NJ, Shorter RG, Phillips SF, Zinsmeister AR. Eosinophilic Gastroenteritis: A clinicopathological study of patients with disease of the mucosa, muscle layer and subserosal tissues. Gut 1990;31:54-8.

[7]. Venkataraman S, Ramakrishna BS, Mathan M, Chacko A, Chandy G, Kurian G et al. Eosinophilic Gastroenteritis- an Indian experience. Indian J. Gastroenterol 1998;17:148-9.

[8]. Ishihara S, Kinoshita Y,Schoepfer A. Inflammation Intest. Dis 2016;1:63-69.

[9]. Oyaizu N, Uemura Y, Izumi H, Morii S, Nishi M ,Hioki K: Eosinophilic Gastroenteritis. Immunohistochemical evidence of IgE mast cell mediated allergy. ActaPatholjpn 1985;35:759-766.

[10]. Desreumaux P, Bloget F, Seguy D, Capron M, Cortot A, Colombel J, Janin A: Interleukin 3, granulocyte macrophage colonystimulating fator, and Interleukin 5 in eosinophilic gastroenteritis. Gastroenterology 1996;110:768-774.

[11]. Mishra A, Hogan S, Brandt E, Rothenberg M: An etological role for aeroallergens and eosinophils in experimental esophagitis. J Clin Invest 2001;107:83-90. 